\title{
EDITORIAL
}

\section{OR and project management}

Projects are a way of life for operational researchers. We work on them, we manage them, and occasionally we help clients to manage their own projects. On the basis of what most OR textbooks and courses contain, one might be forgiven for supposing that operational researchers see project management primarily as the application of a number of activity planning and control techniques. Activity networks, critical path analysis, PERT and so on, are apparently standard techniques with which any self-respecting operational researcher is expected to be familiar. Yet how many practitioners are called upon to apply these techniques? Fewer and fewer, one suspects, as time goes by. The reason for this is not that such techniques are not useful, but that they have become an integral part of the efficient and effective management of any substantial project. Professional project managers, for example in engineering and construction, are fully versed in the use of project planning and control techniques. Moreover, with the availability of sophisticated project planning software packages, these professional specialists have no need to call in the OR (general?) practitioner. In a way of course, this is a success story for OR; would-be clients have adopted a number of OR techniques as standard practice.

This is certainly true for projects which are sufficiently large and complex and which involve obvious logistical problems - like, for example, most construction projects. But, for many other types of project, formal project planning techniques are not used at all. This may be attributable to ignorance or lack of experience with the techniques, but an alternative explanation is that, for many types of project, these techniques are not particularly helpful. Unless complexity reaches a certain threshold level, those involved in managing a project may operate simply by setting project milestones and attempting to progress all intermediary tasks as quickly as possible. This is an effective, robust strategy where many parallel tasks are involved, although inefficiences are likely to arise where limited resources are shared with other projects. Very often there is even a failure to specify a sufficiently detailed work-breakdown structure. A mental map of the required activities, with all its shortcomings, is often all that exists. This sorry state of affairs might sometimes be the result of inadequately thought-out projects being progressed under time pressure and limited human resources. To the extent that this scenario is a fair description of the management of certain types of project, there may be scope for extending typical project planning software to assist project managers in identifying and structuring project tasks. This is a theme explored in Bob Grover's article on page 9, reprinted from the Association of Project Managers' bulletin, Project. Could this be an opportunity for operational research? Well, possibly. While Bob's article focuses on IT projects, expert systems might be practicable for specifying and structuring tasks in other specialized kinds of project. OR could provide invaluable assistance here.

There is, however, another reason for reprinting Bob Grover's article, and that is the thought that OR practitioners might consider applying the ideas contained therein to the management of their own projects. Indeed, it is tempting to suggest that the above scenario of informal project management is typical of the way in which a majority of OR projects are managed, and that more systematic project management is needed. However, this is perhaps unfair. A feature of most OR projects is that they are less about producing a prespecified end-product than about exploring a perceived problem and developing a suitable response. The former process warrants an emphasis on planning the steps needed to bring about the desired end-product: the latter does not. In the latter case the end-product is not well defined and there is, at least initially, great uncertainty about the activities required and often the time required to produce an acceptable result. In these circumstances effective project management requires (among other things) an appreciation of the nature of the OR process in order to track and consider progress; the management of client expectations; judgements about the cost-effectiveness of approaches adopted; concern for the implementability of proposals; and cost-effective deployment of human resources across a portfolio of projects. These and other related issues have been discussed separately and frequently in the OR literature, usually under headings such as "methodology" or "implementation". However, with a few exceptions (including Michael Norman's article "Managing OR in a consultancy", OR Insight Spring 1988), very little seems to have been written about the problems of managing $O R$ projects as an integrated process.

Of course, these problems are not peculiar to $O R$ projects. There is growing awareness amongst project managers in a wide range of industries that project management is much more than the application of project planning and control techniques, and that projects everywhere raise similar management issues. This has led to a burgeoning literature and interest in project management as a subject in its own right. OR practitioners should make every effort to inform themselves of developments in this important new subject area. 